Maya_choghari@hotmail.com

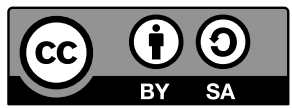

\title{
LOS PARADIGMAS VERBALES EN PAPIAMENTO - UNA HERENCIA AFRICANA BIEN ARRAIGADA EN UN CRIOLLO HISPÁNICO
}

\author{
«El único rincón de serenidad fue establecido por los pacíficos negros \\ antillanos que construyeron una calle marginal, con casas de madera \\ sobre pilotes, en cuyos pórticos se sentaban al atardecer cantando himnos \\ melancólicos en su farragoso papiamento.»» \\ (García Márquez 1987: 305)
}

El papiamento es una lengua criolla, perteneciente a la familia de las lenguas romances, de base española, ${ }^{1}$ hablada por aproximadamente unas 200.000 personas en tres islas caribeñas, las así denominadas Islas de Sotavento -Aruba, Bonaire y Curazao- situadas a unos 80 kilómetros al norte de la costa venezolana. A pesar de haber sido reconocida como lengua cooficial hace apenas una década, el criollo ya tiene desde hace un tiempo una ortografía oficial establecida en $1976^{2}$, fue introducido como materia en las escuelas primarias desde 1986, está en el currículo de las materias que forman parte de los exámenes obligatorios finales de la escuela secundaria desde 2010, además existe como estudio de grado desde 2001 y de posgrado desde 2009 para formar a futuros profesores en la Universidad de Curazao. La situación privilegiada que tiene el criollo hoy en día ha sido fruto de un recorrido largo, de una lucha, un camino lleno de obstáculos que tuvo que superar. Al inicio fue clasificado como un patois, como un conjunto que en realidad no es una lengua. Fue definido como «holandés chapurreado por los indígenas de las Indias

\footnotetext{
1 Hay lingüistas que defienden la teoría monogenética según la cual el criollo es una lengua romance pero de origen lusitano. Según estos científicos «el papiamento es una reedificación de un criollo afrolusitano formado en África occidental en el siglo XVII, y que forma la base de casi todas las lenguas criollas de base afroeuropea» (Lipski 2004: 194).

2 La ortografía oficial en Curazao se basa en la que propusieron Römer, Maduro y Jonis, que publicó Maduro en 1953, mientras que Aruba aceptó una «ortografía medio fonológica, medio etimológica propuesta por la Comisión Mansur» (Munteanu 1996: 69). Bonaire optó por la ortografía curazoleña.
} 
Occidentales; español corrompido; negro español, una jerga a base, principalmente, de un castellano simplificado; a mixture of Dutch, Spanish, English, French, Portuguese and Indian [...]» (van Wijk en Munteanu 1996: 30) o como negertaaltje o negerspaans ${ }^{3}$.

Para poder entender la causa de estas denominaciones, habría que remontarse al nacimiento del papiamento a mediados del siglo XVII, en Curazao, como un conglomerado de distintas lenguas: español, holandés, portugués, inglés, africano del este, de la lengua indígena, el arahuaco-taíno, francés, gallego y seguro alguna que otra lengua más. Surgió como la lengua de los esclavos que habían permanecido en la isla destinados a las labores domésticas y agrícolas hasta que fue reconocida como lengua cooficial en marzo de $2007^{4}$, junto con el holandés. Desde Curazao la lengua fue llevada a las islas vecinas, primero a Bonaire a finales de siglo XVII, inicios del XVIII y a finales de éste también a Aruba. El documento escrito más antiguo ${ }^{5}$ es un poema anónimo publicado en la capital portorriqueña «en un folleto titulado Descripción de las Fiestas Reales en San Juan de Puerto Rico y otros pueblos de la isla en 1830 [...]» (Munteanu 1996: 44, 45) y fue atribuido a los «mulatos holandeses» (Álvarez Nazario en Munteanu 1996: 45) que residían en el sur.

Hoy por hoy, la lengua es hablada por todas las capas sociales, obreros, profesores, artistas y políticos, indistintamente. Es la lengua de los medios de comunicación, tanto escritos como audiovisuales y sirve de herramienta para la creación literaria. De todo lo anteriormente expuesto queda claro que el papiamento está en su pleno florecimiento y que es portador de un nivel de cultura elevado. Esto va, consecuentemente, de la mano de la conciencia nacional que cada vez se hace más omnipresente y, como consecuencia, la gente es consciente de la riqueza cultural y lingüística que abarca esta lengua.

No obstante, uno no se puede cegar ante el hecho de que la presencia y el papel del holandés en las islas sigue teniendo un rol sumamente importante. De los ocho periódi$\cos ^{6}$ publicados en la isla Curazao, los dos más prestigiosos están escritos en holandés, las bibliotecas están abastecidas principalmente de libros escritos en holandés, la lengua hablada ante el juez es el holandés y en el parlamento el papiamento comparte el espacio con el inglés y el holandés. Asimismo los libros utilizados en las escuelas ${ }^{7}$, tanto en las primarias como secundarias están escritos en esta lengua germánica. Sin embargo, de todo lo destacado, lo más llamativo tal vez sea el hecho de que las mejores novelas escritas por nativos, entre los cuales destacan los más fervientes defensores del criollo en

3 Estas dos denominaciones, la lengüecilla de los negros y el español negro respectivamente, provienen de Bachmann (2007: 87). (Las traducciones del holandés al español son mías.)

4 En Aruba es lengua cooficial desde el año 2004.

5 Según Carel de Haseth (1990: 548) el documento más antiguo descubierto es una carta escrita por Abraham da Costa Andrade a Sarah de Isaac Pedro y Vaz Farro en 1775 en Curazao.

6 Los diarios escritos en papiamento son: Exxtra, La prensa, Bala, Vigilante, Ultimo notisia, Boletin. Los periódicos publicados en holandés son: Amigoe y Antillaans Dagblad.

7 Para esta regla hay una excepción. Existe una escuela primaria en Curazao, fundada en 1987, Kolegio Erasmo, que tiene por completo la única lengua de instrucción el papiamento. Frank Martinus Arion, el gran escritor curazaleño, fue el cofundador de ésta. 
cuestión -Frank Martinus Arion, Tip Marugg, Boeli van Leeuwen o Cola Debrot- fueran escritas y publicadas en holandés. El presente artículo tiene como objetivo primordial el estudio de los tiempos verbales. Cabe señalar que de todo lo heredado del español, como la primera lengua dominante cuando Alonso de Ojeda ${ }^{8}$ y su tripulación descubrieron las islas $\mathrm{ABC}^{9}$ en 1499, el campo donde menos influencia tuvo el español y las demás lenguas europeas, es decir, las lenguas de superestrato, fue justamente en los paradigmas verbales. Si por una parte la influencia africana sobre el léxico no es tan notable por otra, sí se aprecia en los paradigmas verbales.

Consecuentemente, en este artículo me propuse exponer los paradigmas verbales en papiamento, primero exponiendo con un ejemplo la conjugación completa, luego explicando la formación y el uso de los paradigmas verbales, para proceder con el análisis de varios cuentos de la serie Kon Nanzi a nèk Shon Arei i e otro kwentanan antiano di e araña $s a b i^{10}$, recopilados y transcritos por Nilda Geerdink-Jesurun Pinto. Sin embargo, para poder entender qué hacen las conjugaciones basadas en un modelo africano en una lengua criolla hispánica, clasificada por el escritor colombiano García Márquez (1987: 305) como «farragosa», o mejor dicho, por uno de los personajes de su novela Cien años de soledad, ha sido necesario remontarnos a la historia del papiamento.

\section{BREVE INTRODUCCIÓN A LA HISTORIA DEL PAPIAMENTO}

Los vestigios encontrados en Curazao -pinturas rupestres en Rooi Lincon y un cementerio cerca del monte St. Michielsberg- testimonian que la isla estaba habitada ya entre 2.800 y 2.300 a.C, en el caso de las islas ABC por los indios arahuaco-taínos que habían venido en canoas desde la costa venezolana. Éstos vivieron en las islas hasta que llegaron los primeros conquistadores europeos que pertenecían a la Corona española. Alonso de Ojeda fue el primer hombre europeo en pisar estas tierras lejanas, siete años después de que fuera descubierto el Nuevo Mundo por Cristóbal Colón. Rápidamente, los españoles empezaron la acción evangelizadora y colonizadora, con lo cual impusieron a los isleños su lengua y su religión.

Al no haber encontrado ni oro ni otros metales preciosos, perdieron su interés en las islas, inclusive denominaron Curazao La isla inútil. Bajo el mando de dos holandeses, Johan van Walbeek y Pierre le Grand, las islas fueron conquistadas sin mayor esfuerzo en 1634 con lo que la guarnición española se vio obligada a retirarse. Dos décadas más tarde Peter Stuyvesant convirtió Curazao en centro de tráfico de esclavos. Éstos procedían sobre todo del Golfo de Benín, Angola y de Congo. Apenas un 5\% de los esclavos se

8 Los historiadores no están completamente de acuerdo sobre quién descubrió las islas, si fue Alonso de Ojeda, Colón, o el florentino Amerigo Vespucci.

9 Aruba, Bonaire y Curazao son conocidas también como las islas ABC.

10 Cómo Nanzi engañó al Don Rey y otros cuentos antillanos de esta araña sabia (La traducción es mía.) 
quedó en la isla mientras que el resto fue vendido por todo el continente americano como mano de obra barata. Esto era explicable desde el punto de vista de la productividad: «los colonos europeos preferían un negro a cinco indios; [...] [ya que]: en el cultivo de la yuca, por ejemplo, un indio fuerte hacía 12 montones diarios, mientras que un negro hacía 140» (López Morales 1998: 81).

Durante varios siglos las naves iban transportando esclavos africanos al Nuevo Mundo. Era un negocio lucroso que tras varios conflictos entre países europeos terminó con la abolición de esclavitud en $1880^{11}$ y con aproximadamente, unos nueve millones de africanos llevados al otro lado del océano Atlántico. Mientras tanto, llegaron las primeras olas migratorias de judíos a Curazao. Se trataba de los judíos expulsados primeramente de España por los Reyes Católicos y posteriormente también desterrados de Portugal por el rey Manuel I. Estos sefardíes llegaron a representar entre un 30 y un $50 \%$ de la población blanca de la isla Curazao. Lingüísticamente hablando, es un dato importante ya que el color de la tez era decisivo en cuanto a la posición social y, consecuentemente, los sefardíes tenían una mayor influencia lingüística sobre otras lenguas. Las islas pasaron a manos de los franceses por un periodo de cinco años, entre 1795 y 1800. En 1800 empezaron a formar parte del protectorado británico. Pero la Paz de Amnies celebrada en 1802 hizo que las islas volvieran a formar parte de la Corona holandesa, situación que ya no cambiará.

Aproximadamente un siglo más tarde, desde que en 1914 Shell construyó la refinería petrolera en la isla, «el español empezó a ser reemplazado por el holandés para el empresariado, la administración y los conocimientos tecnológicos» (Phaf-Rheinberger 2003: 849). Y así, empezaron a llegar trabajadores de todo el territorio caribeño, como también de las tierras sudamericanas, lo cual dio lugar a una convivencia de numerosas culturas, procedencias, razas y naturalmente, de lenguas.

Pero la comunicación con los países hispanohablantes no terminó allí. Gracias al hecho de que «Panamá se convirtió en un país atractivo para buscar trabajo [...], [asimismo] un número considerable de isleños comenzó a emigrar para trabajar en la industria azucarera en Cuba [...]» (Phaf-Rheinberger 2003: 856) pero también millares de braceros hablantes de papiamento se fueron a Puerto Rico para trabajar en las labores agrícolas (Lipski 2004: 467) durante los dos últimos siglos.

Sin embargo, los curazaleños provenían de un lugar donde su propia lengua no fue valorada como una lengua pública hasta los años 60 del siglo XX y desde mediados del siglo XIX se utilizaba el español como lengua de comunicación oficial «debido a las intensas relaciones comerciales entre Curazao y los países americanos y la presencia de numerosos exiliados políticos, víctimas de los regímenes dictatoriales hispanoamericanos, refugiados en este oasis de estabilidad política» (Munteanu 1996: 48). Todo esto ocurre en una etapa en la que el papiamento todavía no fue considerado como una verdadera lengua, y todavía menos como un instrumento que pudiera facilitar la creación literaria.

11 La ley no se hizo efectiva hasta 1886. En 1883 se abolió la esclavitud en Curazao. 
Afortunadamente, esta situación cambia el 30 de mayo de 1969, una fecha decisiva en la historia de Curazao. Ese día «significó una ruptura al respecto, cuando los hablantes del papiamento reclamaron en manifestaciones públicas el reconocimiento de la dignidad de su lengua y de su cultura. A partir de entonces el papiamento comenzó a abrirse espacios en cada nivel de la vida oficial» (Phaf-Rheinberger 2003: 849), dando lugar al florecimiento de la lengua y el estatus que tiene en la actualidad.

De los documentos conservados se sabe que cuando llegaron los holandeses a las islas, los indígenas ya hablaban español. Al transcurrir los siglos este español recibió numerosas influencias y tras la conquista holandesa el vínculo directo con España se rompió, con lo que se le facilitó una evolución propia haciendo de aquel español hoy una lengua distinta. Si bien es cierto que nada más desaparecer el objetivo por el que fue creado un pidgin éste empieza a fenecer hasta que termina por desaparecer del todo ${ }^{12}$, éste no fue el caso del papiamento. Al pasar los años, décadas y siglos y gracias a la convivencia, que sin duda a menudo era forzosa, de distintas culturas, lenguas y tradiciones se creó una situación multicultural y multilingüística que regía una lengua franca, una lengua para que distintas personas que hablaban distintas lenguas pudieran comunicarse entre sí. Y así, cada quien aportó su grano: los arahuaco-taínos, africanos, franceses, portugueses, ingleses, gallegos, pero sobre todo los sefardíes (quienes hablaban sea portugués, sea español o incluso las dos lenguas), españoles, hispanoamericanos y los holandeses. El papiamento pasó de ser un mero pidgin que servía para todos aquellos que no compartían una lengua común a una herramienta para la comunicación. Finalmente el papiamento se convirtió en una lengua criolla, en la lengua materna de una nación.

\section{EL VERBO EN PAPIAMENTO}

El papiamento posee «un sistema verbal semejante a las configuraciones encontradas en [...] otras lenguas criollas: una raíz derivada del infinitivo o de la tercera persona del singular y una serie de partículas preverbales [...]» (Lipski 2004: 476). Las lenguas africanas poseen un sistema muy distinto al sistema de conjugación de las lenguas romances que está basado principalmente en oposiciones aspectuales.

12 Un ejemplo de esto es el sabir francés que se hablaba en Vietnam que desapareció por completo después de que los colonos franceses abandonaran el país (Crystal 1994: 334). 


\subsection{La conjugación}

A continuación sigue la conjugación completa de un verbo modelo, kanta (cantar): Infinitivo: kanta

Gerundio: kanta o kantando

\begin{tabular}{|l|l|}
\hline PERSONA & PRESENTE DE INDICATIVO \\
\hline 1a SINGULAR & mi' ${ }^{13}$ ta kanta \\
\hline $2^{a}$ SINGULAR & bo ta kanta \\
\hline $3^{a}$ SINGULAR & e ta kanta \\
\hline 1 $^{a}$ PLURAL & nos ta kanta \\
\hline $2^{a}$ PLURAL & boso ta kanta \\
\hline $3^{a}$ PLURAL & nan ta kanta \\
\hline
\end{tabular}

\begin{tabular}{|l|l|}
\hline PERSONA & $\begin{array}{l}\text { PRETÉRITO PERFECTO SIMPLE DE INDICATIVO } \\
\text { PRETÉRITO PERFECTO COMPUESTO DE INDICATIVO }\end{array}$ \\
\hline 1a SINGULAR & mi a kanta \\
\hline 2a SINGULAR & bo a kanta \\
\hline 3a SINGULAR & el ${ }^{14}$ a kanta \\
\hline 1a PLURAL & nos a kanta \\
\hline 2a PLURAL & boso a kanta \\
\hline 3a PLURAL & nan a kanta \\
\hline
\end{tabular}

\begin{tabular}{|l|l|}
\hline PERSONA & PRÉTERITO IMPERFECTO DE INDICATIVO \\
\hline 1a SINGULAR & mi tabata kanta \\
\hline 2a SINGULAR & bo tabata kanta \\
\hline 3a SINGULAR & e tabata kanta \\
\hline 1a PLURAL & nos tabata kanta \\
\hline 2a PLURAL $^{\text {a }}$ & boso tabata kanta \\
\hline 3aPLURAL & nan tabata kanta \\
\hline
\end{tabular}

13 Los pronombres equivalen en español a: $1^{\text {a }}$ yo, $2^{\mathrm{a}}$ tú, $3^{\mathrm{a}}$ él, ella, ello; $1^{\mathrm{a}}$ nosotros/as, $2^{\mathrm{a}}$ vosotros/as, $3^{\mathrm{a}}$ ellos, ellas, singular y plural, respectivamente.

En papiamento no existe la palabra Usted. Se resuelve el problema a través de la utilización de siguientes sinónimos: señor (del español señor) / kabayero (del español caballero) / mener (del holandés: meneer) o señora (del español señora) / yufrow (del holandés: juffrouw) en trato indirecto. A modo de ilustración: Bon tardi, señora mester di ayuda? (Buenas tardes, ¿necesita ayuda?)

14 Cuando el pronombre $e$ (él, ella) va seguido de la partícula preverbal $a$, se convierte en $e l$. 


\begin{tabular}{|l|l|}
\hline PERSONA & FUTURO SIMPLE DE INDICATIVO \\
\hline 1a SINGULAR & mi lo kanta \\
\hline 2a SINGULAR & bo lo kanta \\
\hline 3a SINGULAR & e lo kanta \\
\hline 1a PLURAL & nos lo kanta \\
\hline 2a PLURAL & boso lo kanta \\
\hline 3a PLURAL & nan lo kanta \\
\hline
\end{tabular}

\begin{tabular}{|l|l|}
\hline PERSONA & FUTURO COMPUESTO DE INDICATIVO \\
\hline 1 a SINGULAR & lo mi a kanta \\
\hline $2^{\text {a SINGULAR }}$ & lo bo a kanta \\
\hline $3^{\text {a }}$ SINGULAR & lo el a kanta \\
\hline $1^{\text {a } P L U R A L}$ & lo nos a kanta \\
\hline $2^{\text {a PLURAL }}$ & lo boso a kanta \\
\hline $3^{\text {a PLURAL }}$ & lo nan a kanta \\
\hline
\end{tabular}

\begin{tabular}{|l|l|}
\hline PERSONA & EL POTENCIAL PARA EL PRESENTE \\
\hline 1a SINGULAR & lo mi ta kanta / kantando \\
\hline $2^{\text {a SINGULAR }}$ & lo bo ta kanta / kantando \\
\hline 3a SINGULAR & lo e ta kanta / kantando \\
\hline 1a PLURAL & lo nos ta kanta / kantando \\
\hline $2^{\text {a } P L U R A L ~}$ & lo boso ta kanta / kantando \\
\hline $3^{\text {a PLURAL }}$ & lo nan ta kanta / kantando \\
\hline
\end{tabular}

\begin{tabular}{|l|l|}
\hline PERSONA & CONDICIONAL SIMPLE \\
\hline 1a SINGULAR & si mi kanta \\
\hline 2a SINGULAR & si bo kanta \\
\hline 3a SINGULAR & si e kanta \\
\hline 1a PLURAL & si nos kanta \\
\hline 2a PLURAL & si boso kanta \\
\hline 3aPLURAL & si nan kanta \\
\hline
\end{tabular}




\begin{tabular}{|l|l|}
\hline PERSONA & CONDICIONAL COMPUESTO \\
\hline 1a SINGULAR & lo mi tabata kanta / kantando \\
\hline $2^{\text {a SINGULAR }}$ & lo bo tabata kanta / kantando \\
\hline 3a SINGULAR & lo e tabata kanta / kantando \\
\hline 1a PLURAL & lo nan tabata kanta / kantando \\
\hline $2^{\text {a PLURAL }}$ & lo boso tabata kanta / kantando \\
\hline $3^{\text {a } P L U R A L ~}$ & lo nan tabata kanta / kantando \\
\hline
\end{tabular}

\begin{tabular}{|l|l|}
\hline PERSONA & PRESENTE DE SUBJUNTIVO \\
\hline 1a SINGULAR & pa mi kanta \\
\hline $2^{a}$ SINGULAR & pa bo kanta \\
\hline 3a SINGULAR & pa e kanta (p'e kanta) \\
\hline 1a PLURAL & pa nos kanta \\
\hline $2^{a}$ PLURAL & pa boso kanta \\
\hline 3aPLURAL & pa nan kanta \\
\hline
\end{tabular}

\begin{tabular}{|l|l|}
\hline PERSONA & IMPERATIVO \\
\hline $2^{a}$ SINGULAR & kanta \\
\hline $1^{a}$ PLURAL & kanta \\
\hline $2^{a}$ PLURAR & kanta \\
\hline
\end{tabular}

\subsection{La formación de paradigmas verbales}

En papiamento no existen, como en español, varias clases de conjugación. Es decir, no hay distintos grupos flexionales. El verbo con función predicativa tiene una forma invariable que probablemente procede de una de las formas europeas, sea del presente de indicativo, sea del infinitivo. Para saber de qué persona y de qué número se trata es obligatorio el uso de los pronombres junto a los verbos.

Sin embargo, Munteanu (1996: 375, 376), basándose en la propuesta de Birmingham Jr., propone una clasificación de los verbos en papiamento, tomando en cuenta la terminación. Así, se pueden clasificar los verbos en seis clases, de acuerdo con la terminación: 1. verbos en -a (átona o tónica): papia (hablar), buska (buscar), kumindá (saludar);

2. verbos en -e (átona o tónica): bebe (beber), skonde (esconder), komprondé (comprender);

3. verbos en -i (átona o tónica): skibi (escribir), pidi (pedir), wòri (del inglés worry: preocuparse);

4. verbos en consonante: hür (del holandés huren: alquilar), yag (del holandés jagen: cazar), djòin (del inglés: join: unir(se)); 
5. verbos en $-\mathrm{u}$ átona de origen holandés: sòru (de zorgen: cuidar), fangu (de vangen: atrapar), pupu (del holandés poepen: defecar);

6. verbos en diptongo: drei (del holandés draaien: girar), kai (caer), hui (huir).

Para expresar diversos valores temporales y modales se emplea una serie de partículas, resumiendo a Munteanu (en Alvar 1996: 76):

ta (proveniente del español y / o del portugués estar): es utilizado en las perífrasis verbales con gerundio para lo habitual y lo progresivo;

$a$ (del español haber; portugués haver): para el pasado y lo perfectivo;

tabata (taba + ta estar $_{\text {imperfecto }}+$ gerundio): para lo imperfectivo y lo progresivo; lo (del portugués lôgo, español luego): para el futuro e irrealis. «Si el sujeto es pronominal, la partícula lo, se antepone al sujeto: lo mi traha "trabajaré"; si el sujeto es un sintagma nominal, lo ocupa la posición preverbal: Maria lo traha» (Lipski 2004: 476); Especialistas, entre los cuales destacan José Pedro Rona, Germán de Granda y Carmen Valeriano Salazar (Munteanu en Alvar 1996: 76), sostienen que «las partículas del paradigma papiamento son [en realidad] de origen africano y pertenecen a un sistema basado en categorías aspectuales binarias (perfectivo $\sim$ imperfectivo, continuo $\sim$ no continuo)». No obstante, «el sistema africano [...] se fundió con el español, en la medida en que los elementos de ambos no eran irreconciliables» (Munteanu en Alvar 1996: 76). Consecuentemente, este hecho condujo a que el sistema verbal español se simplificara, además de que se asimilaran los valores aspectuales. Como resultado el papiamento obtuvo un sistema verbal bastante simplificado, en comparación con el sistema español u otras lenguas romances, con el que puede «expresar tanto los valores del sistema base como los de las lenguas africanas, sin necesidad de recurrir a perífrasis» (Munteanu en Alvar 1996: 76).

\section{4}

\section{ANÁLISIS VERBAL}

Para el análisis verbal opté por fragmentos de ocho cuentos del libro Kon Nanzi a nèk Shon Arei $i$ e otro kwentanan antiano di e araña sabí (Geerdink-Jesurun Pinto 2012). Los cuentos fueron seleccionados por la variedad de tiempos verbales que contienen para así ilustrar el mayor número de paradigmas verbales dentro del contexto. Los cuentos en cuestión son:

1. Kompa Nanzi i Kompa Tiraleu ${ }^{15}$ (pp. 25-35);

2. Shon Arei ku Kompa Nanzi (pp. 66-69);

3. Kon Nanzi a nèk Diabel (pp. 70-74);

4. Nanzi ku e kulebra Barbakiná (pp. 80-85);

15 Las traducciones de los títulos equivaldrían a: "El compadre Nanzi y el compadre Arrojalejos"; "El Don Rey y el compadre Nanzi"; "Como Nanzi engañó al Diablo"; "Nanzi y la culebra Barbakiná”; "El Don Rey le da a Nanzi un pedazo de tierra"; "Nanzi y la comadre Águila"; "Cómo el compadre Nanzi engañó al Don Rey" y "El escupitajo de Nanzi”. (Las traducciones de los títulos son mías). 
5. Shon Arei ta duna Nanzi un pida tera (pp. 105-109);

6. Nanzi ku Koma Warawara ${ }^{16}$ (pp. 110-119);

7. Kon Kompa Nanzi a nèk Shon Arei (pp. 164-170);

8. Skupi di Nanzi (pp. 180-190).

Dichos cuentos, fruto de la creatividad de un pueblo ghanés llamado Ashanti, llegaron al Nuevo Mundo con los esclavos africanos durante el periodo de la trata. Se transmitían de generación en generación por vía oral. Dado a su extensión geográfica, surgieron algunas diferencias entre las narraciones. Sin embargo, todos estos cuentos tienen un origen común y por lo general, «tienen como protagonista a algún animal que, en los cuentos del Caribe, vence siempre a su rival por medio de trampas y engaños» (Munteanu 1996: 51). La serie más conocida es la de los cuentos de Kompa Nanzi que es una «figura común en el folklore de varios pueblos de la región caribeña» (Munteanu 1996: 51). Según aclara Joubert (en Munteanu 1996: 51) se trata en realidad de Ananse de la Costa de Oro de África, «criollizado bajo las formas Ananzy, en Surinam, Unancy, en Jamaica, o Auntie Nancy, en el sur de los EE.UU.» o como Kompa Nanzi en las islas ABC.

En este apartado se presentan diferentes tiempos verbales ejemplificados con partes de los textos seleccionados para así poder ofrecer un contexto. Todos los fragmentos van acompañados por mis traducciones. Cada ejemplo viene marcado por dos números, el primer número es el número dado al cuento en este artículo y el segundo es la página del libro de Jesurun Pinto-Geerdink (2012) del que proceden los cuentos.

Hay que destacar que no figura ningún ejemplo del condicional compuesto en ninguno de los cuentos del libro. Este tiempo forma parte del potencial en papiamento, que «sirve para establecer una concordancia temporal cuando se expresa una hipótesis real de tiempo pasado en la oración principal acción futura en la oración subordinada» (Munteanu 1996: 353). Hay tres tipos de potencial: lo mi ta kanta / kantando ${ }^{17}$ (estaré cantando), lo mi tabata kanta / kantando (estaría cantando), lo mi a kanta (habré cantado). Los primeros dos ejemplos expresan un aspecto hipotético, continuativo imperfectivo, y el tercer ejemplo un aspecto hipotético, continuativo perfectivo. En cuanto a la voz pasiva, afirma Lipski (2004: 476) que «el papiamento es la única lengua criolla que cuenta con una verdadera construcción pasiva [...]». Ésta se forma combinando los verbos auxiliares ser, keda de origen español, y wòrdu, que proviene del verbo holandés worden, que significa volverse, convertirse, hacerse, ponerse. Sin embargo, el papiamento evita en lo posible esta forma y la «sustituye por construcciones activas o reflexivas impersonales» (Munteanu 1996: 344, 345). Consecuentemente, en los cuentos no hay ningún ejemplo de la voz pasiva.

16 En esta historia aparece una referencia al puerto venezolana Vela de Coro que en papiamento, adaptándose a la escritura, es Bela di Koro (2012: 111, 113).

17 Los tres ejemplos son sacados de Munteanu, 1996: 352, 353. 


\subsection{Presente de indicativo}

El presente de indicativo puede expresar una acción simultánea al momento del habla, una acción repetida o habitual en el presente, una acción posterior al momento de habla o una acción repetida o habitual en el fututo. Es decir, es algo real, continuo e imperfectivo.

E sirbidó di ku Shon Arei ta spera Nanzi pa hasié un fabor. (2: 66) (El servidor le dijo que el Don Rey le espera a Nanzi para hacerle un favor.)

Bo ta weta e bloki ei? (2: 67) (¿Ves aquel bloque?)

Den mardugá mi ta bai pa mi ta bèk banda di nueb’or. (6: 111) (Me voy en la madrugada para estar de vuelta para las nueve.)

\subsection{Pretérito perfecto simple / pretérito perfecto compuesto de indicativo}

Este tiempo verbal es utilizado para expresar acciones reales, perfectivas en el pasado, el resultado en el presente de una acción pasada (pretérito perfecto compuesto de indicativo), para acciones no repetidas y especificadas en el pasado o para un aspecto hipotético no continuativo, perfectivo. Las traducciones que acompañan los ejemplos bien podrían ir en pretérito perfecto compuesto ya que el papiamento desconoce la oposición entre el pretérito perfecto simple y el pretérito perfecto compuesto.

Nanzi a laga tur kos para i el a bai tende ta kiko. (2: 66) (Nanzi lo dejó todo y se fue a ver qué pasaba ${ }^{18}$.)

Ku un kurason kontentu Nanzi a bai drumi. (5: 106) (Satisfecho, Nanzi se fue a dormir.)

Matanan a marchitá i muri. Kunukunan a seka. (1: 25) (Las plantas se marchitaron y se murieron. Las granjas se secaron.)

\subsection{Pretérito imperfecto de indicativo}

El pretérito imperfecto de indicativo expresa un aspecto real, imperfectivo en el pasado o una acción repetida habitual o no especificada en el pasado.

Shi Maria ku Kompa Nanzi i tur nan yunan tabata bira dia pa dia mas flaku. (1: 25) (Día tras día, Doña María y el compadre Nanzi y todos sus hijos se estaban volviendo más delgados.)

Mashá dia kaba tur sóldà, sirbidó y kriá di Shon Arei tabata biba den sustu i spantu. (8: 180) (Desde hace muchos días todos los soldados, sirvientes y criados del Don Rey estaban viviendo en susto y espanto.)

18 Este verbo traducido al español con el imperfecto de indicativo en papiamento es utilizado en pretérito perfecto simple / compuesto. 


\subsection{Futuro simple de indicativo}

El futuro simple de indicativo es utilizado para expresar una acción posterior al momento del habla o para acciones repetidas o habituales en el futuro. Se trata de una acción hipotética, continua e imperfectiva.

Esun ku por trese e ladron pa mi, lo mi duna mil florin. (8: 180) (Le daré mil florines ${ }^{19}$ al que pueda traerme el ladrón.)

Na kaminda lo mi studia un plan. (5: 105) (En camino haré un plan.)

Dios lo rekompensá Shon Arei. (5: 106) (Dios le recompensará, Don Rey.)

\subsection{Futuro compuesto de indicativo}

El futuro compuesto de indicativo forma parte del potencial en papiamento. Es compuesto con el morfema lo en combinación con el tiempo $a$, lo que indica un aspecto hipotético, no continuativo y perfectivo.

Si bo a morde mi mihó, lo mi a muri, ma bo mes ta mira kon tánkatan mi ta? (4: 83) (Si me hubieras mordido con más fuerza, estaría muerto, pero puedes ver por ti misma que estoy vivito y coleando.)

Lo el a hoga dia bieu. (7: 169) (Seguro ya habrá muerto.)

\subsection{El potencial}

En las descripciones tradicionales, los valores del modo potencial «se expresan en papiamento mediante una combinación entre el morfema lo y los morfemas de los demás tipos ta, a, tabata» (Munteanu 1996: 352). Este modo es utilizado para expresar un aspecto hipotético, continuativo imperfectivo o perfectivo.

Para el potencial del presente se utiliza lo en combinación con el morfema que indica el presente $t a$, y su uso es «para establecer una concordancia temporal cuando se expresa una hipótesis real de tipo tiempo pasado en la oración principal, acción futura en la oración subordinada» (Munteanu 1996: 352).

Ma Nanzi lo no ta Nanzi, si suerte no a bolbe kompañ'é (6: 118). (Pero Nanzi no sería Nanzi si la suerte no volviera a acompañarle.)

\subsection{Condicional simple}

Dentro de la categoría del potencial, representan una situación particular «las oraciones subordinadas condicionales introducidas por $s i$, que no siguen el modelo español»

19 Unidad monetaria de las islas ABC y la antigua unidad monetaria de Países Bajos, antes del euro. 
(Munteanu 1996: 353). Así, pueden expresar una hipótesis real en la oración principal (la oración subordinada va en indicativo) o, la oración principal puede expresar un deseo, una orden (se utiliza el imperativo y en la oración subordinada el potencial).

Ma Nanzi ta blo ta pensa numa: si mi pone sufisiente simia i planchi na kas e pida tera ta bini di su mes. (5: 105) (Pero Nanzi no dejó de pensar: si pongo las semillas y las plantas suficientes en casa, el pedazo de tierra ya llegará solo.)

Djipopo $^{20}$, kana numa, mi feter di sapatu a lòs; si mi no mar'é, mi ta trompeká. (8: 184) (Djipopo, sigue caminando. Mis cordones de los zapatos están sin atar, si no los amarro me caigo.)

\subsection{Presente de subjuntivo}

El modo subjuntivo tiene un único tiempo. La reducción de los tiempos del subjuntivo español es explicable si se tienen presente algunos aspectos. En el «español estándar se manifiesta la tendencia a renunciar a los tiempos futuros $[\ldots] \mathrm{y}$, en el habla cotidiana, a restringir en general el paradigma subjuntivo [...], [o] la tendencia general de diferentes variedades americanas del español a reducir el paradigma verbal y a evitar las formas analíticas» (Munteanu 1996: 355). Por otra parte, «los tiempos verbales se han conservado en español, en gran medida, gracias a la correspondencia de los tiempos entre el indicativo y el subjuntivo» (Munteanu 1996: 355).

El subjuntivo en papiamento se utiliza cuando se expresan votos, exhortaciones y deseos. Si la oración principal expresa duda en papiamento, la oración subordinada va en indicativo. Según Maurer (en Munteanu 1996: 357) el presente o el futuro de indicativo pueden expresar las mismas funciones si van acompañados del adverbio de modo como kisas (quizás).

Ma mi no ke pa bo grita ni kanta ${ }^{21}$, mientras bo ta his'é, kargué bai kuné. (2: 67) (Pero no quiero que grites ni cantes mientras $10^{22}$ levantas y te lo llevas).

\subsection{Imperativo}

El imperativo tiene en papiamento los mismos usos que en el español: «se utiliza con función apelativa para expresar órdenes, ruegos, deseos, prohibiciones [...], tiene una entonación apelativa e indica el valor temporal de presente o futuro más o menos mediato» (Markič 2010: 80). A diferencia del español, el pronombre átono en papiamento nunca se une físicamente al imperativo.

20 Es el nombre de uno de los hijos de Nanzi.

21 Se trata de una elipsis, Ma mi no ke pa bo grita ni (pa bo) kanta [...] (2: 67).

22 Lo se refiere a un bloque. 
Ban Nanzi, sigui mi. (2: 66) (Ven Nanzi, sígueme.)

Yuda mi antó! (3: 70) (¡Entonces, ayúdame!)

Bisa mi libremente kiko bo ke, Nanzi. (5: 105) (Dime libremente qué quieres Nanzi.)

\subsection{Verbos reflexivos}

La voz reflexiva puede ser expresada de tres maneras. En primer lugar, a través del pronombre personal con valor reflexivo antepuesto al verbo: Ta bon, mi ta bai unbé. (2: 66) (Está bien, me voy pronto). Mi yama Tiraleu. (1:27) (Me llamo Arrojalejos).

En segundo lugar, por medio del pronombre posesivo + mes (del mismo): Den su mes e ta pensa: ta ken a manda mi? (6: 116) (Pensó: ¿quién me mandó?, es decir, Pensó: es mi culpa.)

En tercer lugar, mediante el sustantivo kurpa, que proviene del sustantivo español, cuerpo: Morto kansá el a tira su kurpa abou na suela. (1: 26) (Muerto de cansancio se tiró al suelo.) Cha Tiger a skonde su kurpa den un kueba. (8: 190) (Cha Tiger se escondió en una cueva.)

\section{$5 \quad$ CONCLUSIÓN}

Para poder entender el porqué de la adjetivación puesta en boca de un personaje por el escritor colombiano García Márquez (1987: 305) en su obra Cien años de soledad al papiamento como una lengua «farragosa» fue imprescindible seguir su transcurso histórico, desde su cuna cuando era un pidgin subordinado a varias lenguas europeas hasta que se emancipó, se convirtió en un criollo y fue declarado lengua cooficial.

El papiamento es, pues, una lengua criolla de base hispánica pero que a su paso al romperse el lazo directo con España, fue integrando influencias de lenguas tan diversas como del arahuaco-taíno, africano del este, gallego, francés, inglés, holandés, portugués, variantes americanas del español y seguro que hay alguna que otra influencia más. Esta mezcla desigual siguió su propio camino de evolución, pasó de ser la lengua de los esclavos a una lengua materna de tres islas caribeñas.

Si bien es cierto que en gran parte el vocabulario y la gramática es herencia de las lenguas ibéricas, especialmente del español, la categoría menos influenciada por éstas se puede percibir en los paradigmas verbales. Por lo tanto, el presente artículo ha tenido como meta principal exponer el sistema verbal del papiamento. Se ha presentado el modo de la formación de los paradigmas para pasar a la ilustración de lo expuesto a través de ejemplos procedentes de ocho cuentos típicos del folklore curazaleño, los cuentos de la araña sabia Nanzi. 


\section{BIBLIOGRAFIA}

ALVAR, Manuel (1996) Manual de dialectología hispánica. El español de América. Barcelona: Editorial Ariel, S.A.

CHOGHARI, Maya (2015) El papiamento - un criollo hispánico. Papiamento - Španski kreolski jezik. Magistrska naloga (tesis de maestría inédita). Ljubljana.

CHOGHARI, Maya (2015) El papiamento - un tesoro lingüístico. Verba Hispanica XXIII. Ljubljana: Znanstvena založba Filozofske fakultete Univerze v Ljubljani: 275-291.

CRYSTAL, David (1994) Enciclopedia del lenguaje de la Universidad de Cambridge. Madrid: Taurus Ediciones.

GARCÍA LEÓN, David Leonardo (2011) Las lenguas criollas del Caribe: Orígenes y situación sociolingüística, una aproximación. Forma y función, vol. 24, núm. 2, julio-diciembre, 40 - 67. Bogotá: Universidad nacional de Colombia. 20 de octubre de 2015. http://www.redalyc.org/artículo.oa?id=21925446003/

GARCÍA MÁRQUEZ, Gabriel (1987) Cien años de soledad. Madrid: Ediciones Cátedra, S.A.

GEERDINK-JUSURUN PINTO, Nilda (2012) Kon Nanzi a nèk Shon Arei i otro kuentanan antiano di e araña sabi. Hoe Nanzi de koning beetnam en andere Antilliaanse verhalen over de slimme spin. Curazao: Instituto Raúl Römer.

HASETH, Carel de (1990) Een bijdrage in de discussie over het ontstaan van het Papiaments. De Gids. Jaargang 153. Amsterdam: Meulenhoff Nederland, 548557. 29 de septiembre de 2015. http://www.dbnl.org/tekst/_gid001199001_01/_ gid001199001_01_0090.php

LIPSKI, John M. (2003) Contacto de lenguas en el Caribe hispánico: implicaciones para el español caribeño, 43 - 60. 1 de abril de 2016. http://www.personal.psu.edu/jml34/cont. pdf/

LIPSKI, John M. (2004) Las lenguas criollas de base hispana. Lexis XXVIII. 1-2, 461508. 27 de febrero de 2016. http://www.revistas.pucp.edu.pe/index.php/lexis/article/viewFile/9199/9608/

MARKIČ, Jasmina (2010) El verbo en español. Aspectos teóricos de la morfosintaxis del verbo español. Ljubljana: Filozofska fakulteta Univerze v Ljubljani.

MEDINA LÓPEZ, Javier (1997) Lenguas en contacto. Madrid: Arco Libros, S.L.

MUNTEANU, Dan (1996) El papiamento, lengua criolla hispánica. Madrid: Editorial Gredos, S.A.

PHAF-RHEINBERGER, Ineke (2003) El papiamento y una narrativa de la modernidad: indagación literaria de la música popular en Curaçao. Revista Iberoamericana, volumen LXIX, número 205, octubre- diciembre 2003, 461—508.

VELLEMAN, Barry L. (2008) La imagen y los ecos del lingüista profesional: La correspondencia de Rodolfo Lenz. RLA, Revista de Lingüística Teórica y Aplicada. 46 (1), I Sem. Concepción (Chile), 11-28. 17 de febrero de 2016. http://www.scielo. cl/scielo.php?script=sci_arttext\&pid=S0718-48832008000100002/ 
POVZETEK

\section{Spregatev v papiametnu - globoko zakoreninjena afriška dediščina v španskem kreolskem jeziku}

Papiamento je kreolski jezik, ki ga govori približno 200.000 ljudi na treh karibskih otokih: Arubi, Bonairu in Curaçaou. V začetku 20. stoletja si je izboril status drugega uradnega jezika (poleg nizozemščine).

Privilegij, ki ga ima danes, je rezultat generacij, ki so ga bile prisiljene uporabljati več stoletij v senci jezikov, ki so jih prinesli s seboj kolonizatorji.

Zahvaljujoč zgodovinskim okoliščinam in mešanici ljudi, ki je bila prisiljena sobivati na majhnem karibskem otoku, se je tako rodil jezik - jezik sužnjev - z namenom, da bi se prebivalci lahko sporazumevali.

Jezik vsebuje vidne sledi avtohtonega prebivalstva Arawakov, afriških jezikov, portugalščine, galicijščine in francoščine, predvsem pa nizozemščine in španščine.

Večji del slovnice in besedišča je papiamento podedoval iz iberskih jezikov ter nizozemščine. Izjema so glagolske spregatve, ki so v veliki meri afriška dediščina. Glavni cilj tega članka je predstaviti to izjemo, ki je podkrepljena s primeri iz tipičnih folklornih zgodb o pametnem pajku Kompa Nanziju.

Ključne besede: papiamento, zgodovina, spregatve, analiza glagolskih časov, Kompa Nanzi.

\section{ABSTRACT \\ The Conjugation in Papiamentu - a deeply-rooted African Heritage in a Hispanic Creole language}

Papiamento, a creole language spoken by approximately 200,000 people on three Caribbean islands: Aruba, Bonaire and Curaçao earned an official status at the beginning of the 21 st century besides Dutch.

Due to historical reasons and thanks to a unique mixture of people of different origins living together on a small island, a pidgin language was born. Throughout the years and as a language of the slaves, it has evolved into a creole language.

Overall, this language contains traces of the ancestral Arawak language, influences of African languages, of Portuguese, French, English, Galician, but mostly of Dutch and Spanish.

The biggest part of Papiamento's vocabulary and grammar is derived from Iberian languages, especially from Spanish, but also from Dutch, however the paradigms are the category that is least influenced by these. 
This article's main objective is to portray Papiamento's conjugation system of African heritage, which is accompanied by examples from folkloric stories of the smart spider Kompa Nanzi.

Key words: Papiamento, history, conjugation, tense analysis, Kompa Nanzi.

\section{RESUMEN}

El papiamento, lengua criolla hablada por aproximadamente unas 200.000 personas a lo largo de las tres islas caribeñas Aruba, Bonaire y Curazao, ha ido ganando desde los principios del siglo XXI el estatus de lengua oficial junto con la lengua holandesa.

Encontramos las causas de los orígenes del pidgin en razones históricas y sobre todo gracias a una mezcla única de personas de diferentes orígenes que convivieron en las pequeñas islas donde a lo largo de los años y como lengua de los esclavos dicha lengua se fue desarrollando para convertirse finalmente en una lengua criolla.

En general, esta lengua contiene vestigios de la ancestral lengua arahuaco-taíno, influencias africanas así como de las lenguas portuguesa, francesa, inglesa, gallega, y sobre todo de la holandesa y española.

La mayor parte del léxico y de la gramática del papiamento deriva de lenguas ibéricas, especialmente del español, así como del holandés, aunque no sucede lo mismo con los paradigmas verbales, la categoría menos influenciada por dichas lenguas.

El principal objetivo de este artículo es describir el sistema de conjugación del papiamento, de herencia africana, que se acompaña de ejemplos sacados de cuentos folclóricos sobre la araña sabia Kompa Nanzi.

Palabras clave: papiamento, historia, paradigmas verbales, análisis verbal, Kompa Nanzi. 